\section{Educar Para o Mundo: Experiência Extensionista Popular para Direitos Humanos e Migrações}

\author{
Educar Para o Mundo: Popular Academic Outreach \\ Experience in Human Rights and Migrations
}

\section{RESUMO}

A proposta do Educar para o Mundo é repensar a forma como se estuda e se atua na área de Relações Internacionais, especialmente nos projetos de extensão da área, inspirados em autores que pensam criticamente sobre a forma como a área acadêmica se relaciona com a sociedade à qual pertence. A exemplo de Paulo Freire, decidimos ir além da sala de aula para nos inserirmos na realidade dos imigrantes latino-americanos em São Paulo. Iniciamos nosso trabalho em uma escola pública que abrigava uma porcentagem significativa de crianças bolivianas e que tinha uma dificuldade considerável em lidar com este grupo. Após anos de uma relação profícua, porém difícil e desgastante, percebemos que o modelo de escola tradicional com que trabalhávamos oferecia mais barreiras do que novos caminhos para expandir nossa atuação com os migrantes e optamos por fortalecer nossa presença nos espaços públicos e junto aos movimentos organizados de imigrantes. Entendemos que o diálogo com interlocutores ativos e dispostos oferece grandes possibilidades de realizar o trabalho de extensão comunicativa popular. Este artigo apresenta os principais resultados alcançados por nosso coletivo em seus seis anos de existência e debate os caminhos da extensão popular para a área de Relações Internacionais.

Palavras-chave: Extensão Comunicativa. Educação para Direitos Humanos. Migração.

\section{ABSTRACT}

Educar para o Mundo is a collective work aimed at rethinking how the area of International Relations could be studied and acted upon, especially regarding the academic outreach initiatives in the area. It is mostly inspired by authors that think critically about how the academic area relates with the society it belongs to. Following the work of Paulo Freire, we decided to go beyond the classrooms to actively work with

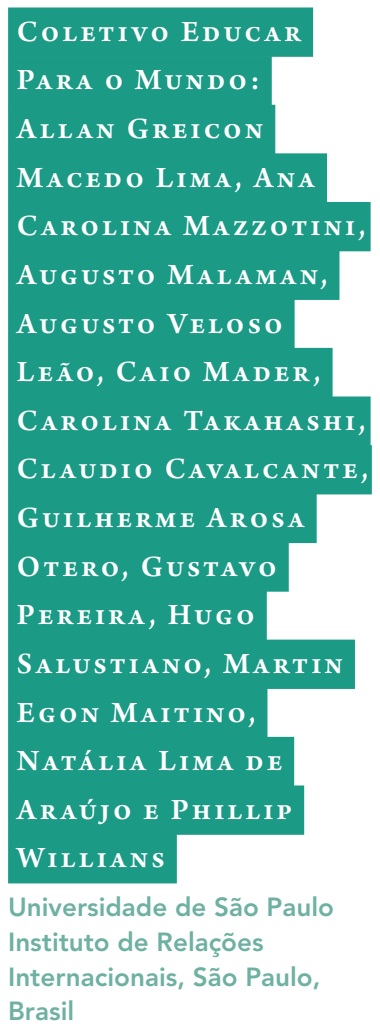

Rev. Cult. e Ext. USP, São Paulo, n. 13, p.65-82, maio 2015 DOI: http://dx.doi.org/10.11606/issn.2316-9060.v13i0p65-82 
the reality lived by Latin-American immigrants in the city of São Paulo. We have begun our work in a public school whose student body includes a significant number of Bolivian-origin children and faced many difficulties in dealing with this group. After years of a proficuous relationship, albeit difficult and demanding, we realised that the traditional educational model presented more barriers than pathways to expand our work with migrant groups and opted to strengthen our presence in public spaces and together with organized migrant social movements. We understand that dialog with active interlocutors offers great chances of doing a communicative outreach work. This article presents our main results in our six years of existence and debates opportunities for popular outreach in the area of International Relations.

Keywords: Communicative Outreach. Education for Human Rights. Migration.

Figura 1 - Oficina de grafite na Praça Kantuta

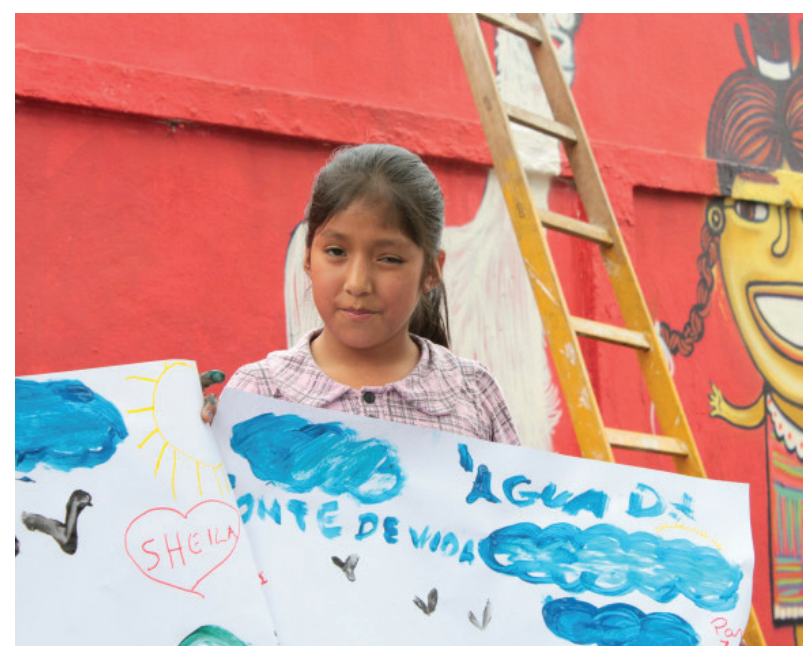

\section{INTRODUÇÃO}

\section{O coletivo de extensão Educar para o Mundo (EpM) surgiu em 2009, por iniciativa} conjunta dos estudantes do curso de Relações Internacionais da Universidade de São Paulo, organizados no Centro Acadêmico Guimarães Rosa, e da professora Deisy Ventura, como um projeto de extensão para trabalhar os direitos humanos dos migrantes e a valorização da cultura latino-americana. A experiência prévia dos estudantes e da coordenadora com o desenvolvimento de atividades de extensão comunicativa popular facilitou os primeiros momentos de criação e elaboração das atividades do coletivo e possibilitou a formação de uma estrutura que trabalhasse com bastante autonomia e mantendo a centralidade da preocupação acadêmica, o que posteriormente possibilitou o surgimento do atual coletivo de extensão. Os objetivos de nossas atividades se concentram em trazer uma perspectiva concreta de prática extensionista para o curso de Relações Internacionais, como alternativa à tendência comum do curso em privilegiar o ensino e a pesquisa em detrimento da extensão, assim como responder à falta de iniciativas para superar a distância 
estabelecida entre esta área acadêmica e a sociedade em que está inserida. Ao mesmo tempo, Relações Internacionais é um curso que estabelece vínculos fortes com o poder institucional e, por vezes, acaba tornando-se pouco afeito a possibilidades de intervenções transformadoras na sociedade.

O trabalho é norteado pelo conceito de pedagogia da autonomia defendido por Paulo Freire e fundamentado eticamente pelos princípios da solidariedade e da hospitalidade. Estes foram os pontos de partida para decidirmos trabalhar com os temas da educação para os direitos humanos e da educação para a valorização da cultura latino-americana, com uma perspectiva especialmente voltada para a inclusão social. O tema da migração internacional foi escolhido por ser central para as Relações Internacionais contemporâneas e garantiu que o coletivo encontrasse seu espaço no ambiente universitário desse campo do conhecimento. O Educar para o Mundo passou, então, a articular o conhecimento acadêmico para possibilitar a construção dos instrumentos básicos de mobilização frente a temas que demandam engajamento da sociedade civil e nos quais os movimentos sociais desempenham papel fundamental. Por esse motivo, nosso trabalho compreende ao mesmo tempo a ação junto aos migrantes, especialmente os latino-americanos, um sólido trabalho junto à comunidade que os acolhe, assim como, a reflexão acadêmica sobre a migração e sobre a própria atuação do coletivo.

Desde seu início, o EpM focou na questão dos direitos humanos dos migrantes latino-americanos na cidade de São Paulo por meio da busca do diálogo horizontal com seus interlocutores: começamos nosso trabalho com a comunidade escolar da EMEF Infante Dom Henrique, no bairro do Canindé, em São Paulo e depois expandimos nosso foco em busca dos espaços ocupados pelas comunidades migrantes e suas entidades. A escola foi escolhida como primeiro local de atuação porque muitos de seus alunos eram imigrantes latino-americanos. Posteriormente, visando articulações com maior diversidade de atores sociais, nosso campo de ação se expandiu da escola para as associações de migrantes. A partir daí, a luta por alterações na legislação migratória e pela efetivação de políticas públicas para os migrantes se tornaram os temas centrais de nossa atuação. Paralelamente, nossas atividades, no contexto da universidade, possibilitaram que discutíssemos também a transformação da estrutura curricular universitária, de modo a torná-la mais próxima da sociedade. Um de nossos maiores esforços é trazer para a área acadêmica o aprendizado construído em nossas experiências externas, através da publicação de artigos, da promoção de palestras, de debates e de exposições.

Este artigo busca sistematizar nossas experiências e atividades ao longo dos seis anos do Educar para o Mundo, apresentando os conhecimentos que acumulamos nas ações desenvolvidas em extensão popular comunicativa e em educação não formal em direitos humanos. Apresentaremos nossos objetivos, atividades e também algumas avaliações sobre nosso trabalho, buscando delinear a metodologia que utilizamos e os resultados obtidos, mesmo que muitos dos resultados sejam, na verdade, difusos e difíceis de medir. Observando nosso histórico de atividades, pretendemos, ainda, demonstrar como um coletivo universitário extensionista pode ter um papel importante no diálogo político entre a sociedade a universidade, bem como contribuir para 
a articulação da sociedade civil com governos e outras esferas da política institucional.

\section{O INÍCIO DAS ATIVIDADES}

A parceria com a Escola Municipal Infante Dom Henrique, localizada no bairro do Canindé, em São Paulo, na qual cerca de $12 \%$ do corpo discente é imigrante *, iniciou-se em 2009. Nosso primeiro passo foi buscar uma aproximação com o corpo docente e com a coordenação da escola por meio de reuniões no espaço da Jornada Especial Integral de Formação (JEIF) e de uma discussão gerada a partir da exibição do filme francês Entre os Muros da Escola, de Laurent Cantet [8]. A discussão possibilitou as primeiras reflexões sobre os problemas enfrentados diariamente naquela escola e pudemos também ver quais eram as dificuldades advindas da grande quantidade de alunos imigrantes. Foi com as discussões realizadas nesses encontros que recolhemos as primeiras indicações de como poderíamos abordar o tema das migrações na escola.

No segundo semestre de 2009, começamos a promover oficinas diversas para debater a questão dos direitos humanos com os alunos, especialmente os alunos da $5^{\mathrm{a}}$ à $8^{a}$ séries. Realizamos encontros quinzenais com atividades livres de troca de saberes e buscamos estabelecer um espaço sem hierarquias e mais informal do que as aulas curriculares. Uma de nossas preocupações era garantir que todos os participantes tivessem a mesma possibilidade e interesse de intervenção. Nessas oficinas, buscamos atividades que facilitassem a aproximação do indivíduo com os temas trabalhando, principalmente através do uso da arte e de elementos culturais, dois aspectos centrais para a educação popular dos direitos humanos.

Ainda em setembro de 2009, realizamos uma oficina de grafite nos muros da Infante Dom Henrique para introduzir a questão da ocupação do espaço público, mas também, como forma de romper o cinza da cidade e do cotidiano daquela região. Acreditamos que o grafite ajudou a estimular o exercício do direito fundamental da liberdade de expressão, especialmente ao promover a discussão sobre a identidade e auto-representação dos alunos e sobre as violações cotidianas aos direitos humanos que eles viviam. Nossa percepção é de que os desenhos da oficina de grafite são uma forma de concretização visual das discussões que realizamos nos encontros e representam a maneira como os estudantes viam e viviam as violações de direitos debatidas.

\footnotetext{
*Dados da própria escola à época indicavam que, em 2009, 85 dos cerca de 800 alunos eram imigrantes ou filhos de imigrantes, a grande maioria bolivianos (Inventário EMEF Infante Dom Henrique, 2009). Em uma tendência similar, o Censo escolar de 2010 estimava que os migrantes correspondessem a aproximadamente 41 mil alunos no Ensino Básico em São Paulo, ou 7\% do total de matrículas [17].
} 


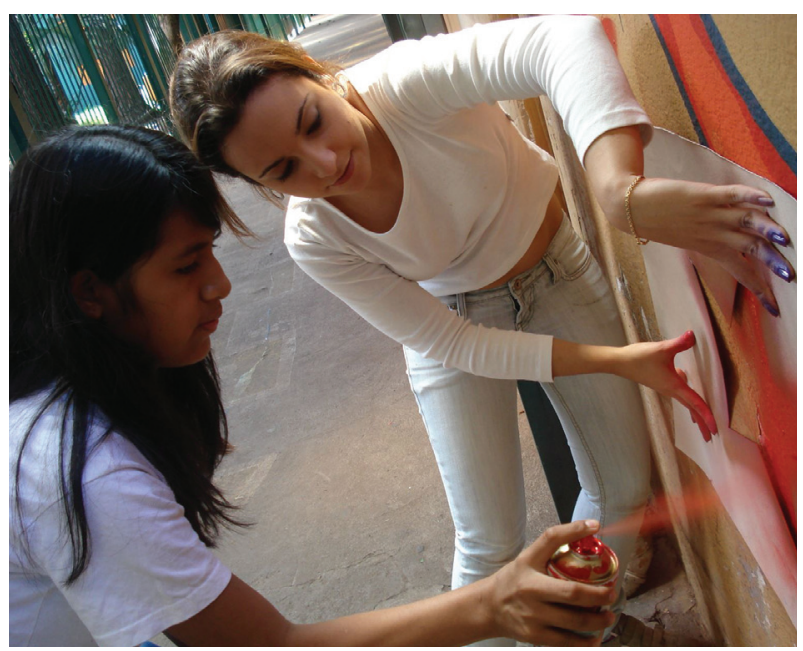

Em outra atividade, uma oficina de quadrinhos, realizamos uma discussão sobre a Declaração dos Direitos da Criança da ONU (1959). Os alunos abordaram os problemas de convivência e de discriminação na escola e no seu dia a dia, assim como as violações dos direitos das crianças que vivenciavam a partir de histórias em quadrinhos digitais confeccionados por eles próprios**. A terceira oficina de 2009 trabalhou a questão da preservação da identidade com atividades de fotografia com máquinas pinhole construídas com caixa de papelão, tinta e papel fotográfico. Com o tema Auto Retrato, os alunos registraram momentos individuais e em grupo, que foram utilizadas para suscitar o debate a respeito de suas autoimagens, da percepção de pertencimento e da identidade de grupo.

Ao longo de 2010, três oficinas proporcionaram um contato mais forte com grupos e movimentos sociais além dos muros da escola, e tiveram o objetivo de aliar as discussões sobre educação pública, espaço público e suas relações com os direitos humanos. Para a primeira oficina, sobre o acesso à educação pública, convidamos educadores do Cursinho Comunitário Pimentas (Guarulhos-SP) para mediar um debate sobre os problemas que os alunos enfrentavam na própria EMEF Infante Dom Henrique. Na segunda oficina, promovemos a discussão sobre os espaços públicos próximos a eles (a escola e as praças da região) e os espaços da USP (incluindo uma visita à Universidade). $\mathrm{O}$ debate acabou por realçar a percepção de que esses espaços não são apropriados pela comunidade do município e os alunos se questionaram se seriam, portanto, espaços verdadeiramente públicos. Na terceira oficina, os alunos organizaram uma exposição das fotos que tiraram na visita à USP e realizamos um debate que buscou conjugar as reflexões das duas oficinas anteriores.

Mais um passo na diversificação das atividades do coletivo foi dado em 2011,

\footnotetext{
** Foram feitos dois vídeos a partir das histórias em quadrinhos. José Luiz Choque apresentou uma história sobre preconceito em uma escola <https://www.youtube.com/watch?v=AWv6B_-2nlE> e Litza criou uma história sobre discriminação de gênero em uma família <https://www.youtube.com/ watch?v=bB83|rAzkXQ>.
} 
quando o Educar para o Mundo participou, junto com o corpo escolar, da elaboração do Projeto Político Pedagógico da EMEF Infante Dom Henrique. A proposta era trazer para o centro das discussões escolares a questão da diversidade, foco do trabalho do EpM e uma preocupação da nova direção da escola. A partir dessa proposta, iniciou-se o planejamento de um ciclo de formações para a comunidade escolar, elaborado em conjunto com os próprios professores, em que utilizamos os Círculos de Cultura"como instrumento para avaliação dos temas a serem trabalhados, visando o aprofundamento da consciência crítica das pessoas envolvidas e o desenvolvimento do Projeto Político Pedagógico. Os temas que resultaram mais relevantes foram a questão da identidade, o direito à educação e o direito à cidadania. Ao mesmo tempo, em uma atividade que unia os alunos e professores do colégio, propusemos um projeto de confecção de uma Cartilha de Direitos Humanos pelos alunos e professores dos Ciclos 1 e 2. Escolhemos cinco direitos humanos - direito à identidade, à educação, à mobilidade, ao lazer e à organização social - e desenvolvemos atividades lúdicas nas quais os alunos eram estimulados a vivenciar cada um desses direitos e estabelecer um novo significado para esses direitos baseando-se em suas próprias experiências.

$\mathrm{Na}$ atividade sobre mobilidade, fizemos um jogo com os alunos, abordando a questão dos símbolos nacionais, como bandeira e hino, e problematizamos várias situações que acontecem durante o trânsito de pessoas, tais como as arbitrariedades dos órgãos de migração, o maior valor dado aos documentos do que aos direitos dos seres humanos, e também os preconceitos e estereótipos em relação àqueles que migram. Na atividade sobre identidade, trabalhamos com a música Gabriela, tratando a questão da identidade como um elemento fluido de nossa personalidade, além da questão do estigma que algumas identidades sofrem e do preconceito com relação a alguns grupos humanos. $\mathrm{O}$ resultado foi sistematizado em uma grande colcha de retalhos formada por pedaços de tecidos pintados pelos alunos, nos quais eles retratavam a maneira como se enxergavam. Dando continuidade a esse trabalho, trouxemos os alunos para dentro da universidade, em uma roda de conversa e uma oficina com o Núcleo de Consciência Negra da USP. Nesta atividade, os estudantes analisaram seus próprios livros didáticos em busca de imagens de negros e negras, com o propósito de introduzir uma discussão sobre a imagem do negro em nossa sociedade e sobre seu papel social. A oficina sobre educação, por sua vez, abordou os limites da educação formal e procurou valorizar o conhecimento não formal: os estudantes compartilharam experiências de coisas que aprenderam fora da sala de aula, com amigos e familiares, especialmente. Os resultados foram sistematizados em um "livro escolar alternativo" confeccionado pelos próprios estudantes. Já na oficina sobre o direito ao lazer, buscamos trabalhar a questão da apropriação do espaço público, levando os alunos a uma praça que existe perto da escola, na qual ocorre, aos domingos, uma das maiores feiras latino-americanas da cidade de São Paulo, a Praça Kantuta. Os estudantes também elaboraram esquetes sobre o tema do direito ao lazer e escolheram os tópicos que desejavam discutir. Alguns esquetes, como, por exemplo, o que abordou a gravidez precoce e sua interferência no lazer dos jovens, demonstra, em nossa opinião, o potencial de politização e visão crítica que esses jovens puderam desenvolver.

Uma das últimas atividades do ciclo sobre os direitos foi a exibição de 
curtas-metragens em um momento de união entre professores e alunos. Nessa atividade, pudemos observar com muita clareza a evolução pela qual haviam passado tanto os alunos e professores da Infante Dom Henrique quanto os integrantes do Educar para o Mundo. A maior evolução que percebemos foi entre os alunos, que propuseram discussões muito interessantes sobre os vídeos com argumentos bastante elaborados e se mostraram muito mais à vontade de manifestar suas opiniões e percepções do que os docentes. Por fim, promovemos um debate sobre o direito à organização política a partir das mobilizações que ocorriam na Universidade de São Paulo no fim de 2011 e que buscavam, principalmente, refletir sobre a falta de segurança dentro da USP e sobre a presença da Polícia Militar dentro do campus. A atividade surgiu do interesse manifestado pelos próprios alunos e, em nossa visão, demonstra o desenvolvimento de uma curiosidade especial sobre movimentos reivindicatórios. No debate, os estudantes estavam interessados em contrastar as percepções contraditórias sobre as mobilizações, que eram muitas vezes reconhecidas como "baderna". Os alunos realizaram, então, uma pesquisa pela escola, perguntando aos funcionários sobre as mobilizações das quais eles haviam participado. Ao final, os estudantes analisaram que a entrevista mostrava a falta de engajamento dos funcionários da escola em questões políticas e os estudantes demonstraram vontade em mudar essa situação, procurando envolver-se nas questões políticas da cidade.

\section{ARTICULAÇÃO COM MOVIMENTOS SOCIAIS E O RETORNO PARA O AMBIENTE ACADÊMICO}

Desde o início de nossa atuação em extensão, procuramos criar e fortalecer iniciativas com movimentos sociais formados por imigrantes, ou que atuam com este público. Consideramos que essas organizações que possuem forte potencial para construir conhecimento e trabalhos inovadores, uma vez que possuem a confiança dos imigrantes e dialogam diretamente com eles, além de apresentar estrutura material e organizacional que possibilitam gerir iniciativas mais elaboradas.

Neste contexto, participamos da criação do Fórum Social pelos Direitos Humanos e Integração dos Migrantes no Brasil (FSDHIM), um grupo formado por diversas organizações da sociedade civil e alguns coletivos. O objetivo deste fórum é a troca de experiências entre as entidades participantes, a construção conjunta de uma atuação política para efetivar a imigração como um direito humano e fundamental, garantindo que o rol de direitos dos imigrantes seja compatível com as obrigações constitucionais e internacionais que o Brasil adota, e a reflexão sobre as iniciativas e as políticas de integração de imigrantes. Em dezembro de 2012, o FSDHIM, o Instituto de Relações Internacionais da USP (IRI-USP - instituição de filiação do Educar para o Mundo) e a Secretaria de Direitos Humanos da Prefeitura de São Paulo, organizaram o seminário "Por uma Política Municipal de Migração em Defesa da Vida e da Dignidade dos Trabalhadores Imigrantes e suas Famílias", que marcou o início de debates constantes sobre a política de migração para a cidade de São Paulo e que culminou finalmente na I Conferência Municipal de Políticas para Imigrantes. O Educar para o Mundo e 
o Fórum atuaram ativamente na construção da Conferência, que foi organizado por entidades da sociedade civil e pela Prefeitura Municipal de São Paulo em novembro de 2013. O Fórum também atuou, por meio de eventos, manifestos e contato com parlamentares, para que se consolide uma mudança na legislação de migração que amplie a proteção aos direitos humanos dos imigrantes.

Nos últimos anos, nossos aliados mais próximos dentro do movimento social de imigrantes são duas organizações não governamentais: o CDHIC - Centro de Direitos Humanos e Cidadania do Imigrante, e o CAMI - Centro de Apoio ao Migrante. No Brasil, a mobilização política de imigrantes é limitada pela legislação da Lei $6815 / 1980$, que impede a organização política de pessoas sem cidadania brasileira. Por causa disso, praticamente toda mobilização política em torno da causa migrante é realizada por ONGs de brasileiros e pelos sindicatos profissionais.

Com o CAMI, o CDHIC e outras entidades que compõem o FSDHIM, o Educar para o Mundo trabalhou na organização das cinco últimas edições da Marcha do Imigrante, que ocorre todos os anos no mês de dezembro e busca dar visibilidade para os diversos temas da causa migrante, além de se constituir em um importante espaço de luta e de formação política. Outro trabalho importante que o Educar para o Mundo realizou em parceria com o CDHIC foi a coordenação da Consulta Regional da Sociedade Civil em preparação ao Diálogo de Alto Nível das Nações Unidas sobre Migração e Desenvolvimento, em junho de 2013. A Consulta foi organizada pela Rede Sul-americana Espaço Sem Fronteiras-ESF, e coordenada pelo CDHIC, com apoio do Educar para o Mundo, da Coalizão Global de Migração-CGM (da qual ESF é associado), da ONG Presença da América Latina-PAL, da Secretaria Nacional de Justiça e do Conselho Nacional de Imigração do Ministério do Trabalho e Emprego. Esse evento foi um instrumento para que a sociedade civil latino-americana pudesse oferecer suas perspectivas sobre o tema da migração para o Diálogo de Alto Nível que ocorreu no segundo semestre na ONU, elaborando conjuntamente um documento apresentando suas demandas para o organismo internacional.

Outra parte de nossa atuação em extensão consiste em trazer para o ambiente acadêmico os conhecimentos que construímos e adquirimos junto à comunidade de imigrantes em São Paulo. Para efetivar esse relacionamento de mão dupla, o Educar para o Mundo se dedica a ser um espaço de formação para os alunos do IRI-USP, promovendo reuniões semanais para discutir os temas de interesse do coletivo, além de organizar mesas de debate e de escrever artigos que efetivem o encontro dos conhecimentos de migrantes e de especialistas. Desse modo, conseguimos trazer para dentro do Instituto de Relações Internacionais da USP o tema dos direitos humanos dos imigrantes a partir de diversas perspectivas. Em nossas reuniões semanais, reservamos um espaço para fazer discussões atualizadas sobre a situação dos migrantes no Brasil e no mundo, debater as lutas políticas e de identidade de grupo que são levadas a frente pelos grupos migrantes e definir a atuação do coletivo com relação às demandas que surgem dos movimentos sociais de imigrantes e das entidades que trabalham os direitos humanos dos imigrantes.

Entre as mesas que promovemos recentemente, estão A Nova Migração Negra no Brasil, inserida no evento Maio Cultural - Sarará Crioulo: as diversas cores do negro, 
do Centro Acadêmico Guimarães Rosa, do IRI-USP, a Etapa Preparatória Livre para a I Conferência Municipal de Políticas para Imigrantesw e um debate sobre a interface possível entre extensão e migração. Em 2014, também realizamos um debate sobre o Anteprojeto de Lei de Migrações do Ministério da Justiça na mesa "Nova Lei Migratória Brasileira", discutimos a participação dos imigrantes nos Conselhos Participativos da cidade de São Paulo e, por fim, trouxemos refugiados de várias nacionalidades para um debate que visava sensibilizar para o tema do refúgio no país. A produção bibliográfica do coletivo compreende uma série de artigos, como o publicado na Revista Ideias, da Universidade de Campinas [16]; e o apresentado no Congresso Ibero-americano de Extensão Universitária, realizado na Argentina, e publicado na Revista Direito \& Sensibilidade [14]. Atualmente, além do EpM, o IRI-USP conta com diversas produções sobre migrações, que é tema de pesquisas de graduação, mestrado e doutorado.

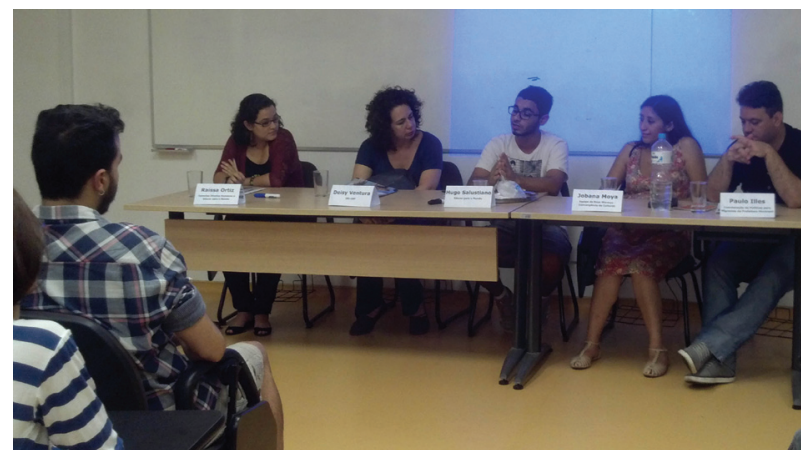

Figura 3 - Mesa Extensão e Migração.

A educação popular, a autogestão e os debates relacionados à extensão comunicativa são também parte das discussões realizadas dentro do Educar para o Mundo. Buscamos realizar uma reflexão constante sobre nosso trabalho e de seu impacto na forma como nos relacionamos com os migrantes, com outros grupos sociais e mesmo entre os próprios integrantes do coletivo. Assim, nossas reflexões também envolvem a própria estrutura e organização do coletivo, uma vez que um de nossos objetivos é que nossos membros possam se apropriar dos conceitos e da prática da extensão comunicativa popular e utilizá-los para uma ação transformadora na sociedade. Para isso, também mantemos contato com outras organizações extensionistas, como o Escritório Piloto (Laboratório Interdisciplinar de Extensão Universitária da Escola Politécnica da USP) e a Frente de Extensão da USP.

\section{ABORDANDO OS DIREITOS JUNTO AOS MOVIMENTOS SOCIAIS DE MIGRANTES}

O Educar para o Mundo procura funcionar de maneira dialógica e realiza atividades que ofereçam oportunidades de aprimoramento para a comunidade de migrantes, 
que é nossa principal interlocutora, e para seus próprios integrantes. Isso significa que boa parte de nossa atuação é pautada pelas demandas dos próprios imigrantes, com base nas situações que eles vivem diariamente. Ao reconhecer esse interlocutor, decidimos nos aproximar mais das organizações envolvidas na luta pelos direitos dos imigrantes, e desenvolvemos atividades concretas de educação popular que fossem pautadas pelas demandas desses movimentos. Foi a partir dessa perspectiva que organizamos oficinas sobre a legislação migratória no país, sobre o Estatuto do Estrangeiro, bem como sobre as propostas de modificação para o Estatuto, principalmente o Projeto de Lei 5655/2009 em tramitação na Câmara dos Deputados desde 2009 e o Projeto de Lei do Senado 288/2013, apresentado em 2013.

Começamos a realização dessas oficinas durante a preparação para a 6a Marcha do Imigrante em 2012, cuja pautou era o trabalho decente e a cidadania universal. Uma imigrante militante, parceira do Educar para o Mundo desde o seu início, questionou o fato de a comunidade migrante estar lutando pelos seus direitos, e, todavia, desconhecia quais eram os dispositivos legais que lhes asseguraria tais direitos e quais eram as leis e regulamentos causadores das restrições e situações degradantes pelas quais os migrantes e refugiados geralmente passam. Surgiu, então, a ideia de realizar as oficinas de legislação para aumentar o entendimento e os debates sobre o tema. Optamos por trabalhar com a Lei 6815/80 - a atual Lei de Imigração Brasileira -, com o Projeto de Lei 5655/o9, que poderá substituir a atual legislação, com o atual Código Penal e com sua proposta de modificação, que cria uma seção especial para os crimes cometidos por imigrantes. $O$ conteúdo das oficinas foi separado em cinco eixos - criminalização da imigração, direito ao voto, meios de comunicação, políticas públicas e acesso a direitos e o código penal. Todos os temas são abordados fundamentados na legislação atual e nos projetos de lei que tramitam para sua modificação.

Nossa avaliação é que esse trabalho é significativo não apenas pelo tema que trata, mas também por ser uma demonstração concreta das possibilidades de atuar baseando-se na pedagogia do educador Paulo Freire. Muitas vezes, conceitos freirianos como "dialogicidade" e "horizontalidade" parecem demasiadamente abstratos, mas se tornam bastante claros com a realização das oficinas. Baseadas na prática extensionista-comunicativa, as oficinas são organizadas de modo a permitir que as intervenções do nosso interlocutor construam um diálogo mútuo, em que o intercambio de ideias possa dar novos significados para as implicações das leis na vida diária dos migrantes. Nesse sentido, ao invés de "depositarmos” informação em nossos interlocutores, as oficinas apresentam uma breve introdução aos temas e, usando os relatos e perguntas do público, apresentamos os assuntos mais profundamente, privilegiando as contribuições dos migrantes para debater a legislação migratória.

Além disso, é importante ressaltar que é objetivo das oficinas que os membros do coletivo também aprendam. Além de sermos confrontados com uma realidade que não é a nossa, os migrantes sempre apresentam questionamentos que não sabemos exatamente como responder. A cada vez que repetimos a atividade, adaptamos o conteúdo das oficinas a partir da demanda concreta dos imigrantes: alguns assuntos que nós considerávamos pertinentes não têm repercussão nos debates dos participantes; ou os próprios migrantes demandam o debate de assuntos sobre os quais não 
havíamos pensado antes que estaria relacionado com a legislação migratória. Por esses motivos, consideramos as oficinas de legislação experiências muito ricas para as e os integrantes do Educar para o Mundo, especialmente por ser uma atividade de educação popular inteiramente formulada para um público adulto migrante. O próximo passo nesse trabalho é o aperfeiçoamento do material escrito das oficinas para auxiliar nos eventos futuros. De acordo com nossa proposta, o conhecimento não deve ficar restrito ao EpM e aos participantes das oficinas, e, ademais, nossos interlocutores podem se tornar replicadores dessas oficinas e promover novos encontros em suas comunidades, discutindo outros temas. Desse modo, mais que organizadores das oficinas, atuamos como facilitadores de conhecimentos sobre a legislação migratória e de como ela impacta a vida do imigrante.

\section{OUTROS ESPAÇOS, OUTRAS INTERVENÇÕES}

O Educar para o Mundo sempre teve em vista a necessidade de atuação em espaços geográficos que são significativos política e socialmente para a nossa comunidade interlocutora. Desde o início, o coletivo buscou intervir diretamente no espaço da Praça Kantuta, importante espaço de expressão cultural latino-americana no bairro do Canindé, local onde vive uma grande parte da população migrante em São Paulo, especialmente a de origem boliviana. Semanalmente, a praça é palco de uma feira cultural, com artesanato, música e comidas típicas de países sul-americanos e foi nesse cenário que decidimos realizar parte do diálogo com a comunidade migrante. Uma das nossas primeiras atividades na Praça foi uma oficina de grafite que propôs uma revitalização do espaço a partir da incorporação de elementos visuais andinos e da história da imigração latino americana no Brasil à praça. Os frutos dessa intervenção ainda podem ser observados na Kantuta e a grafitagem foi uma das primeiras oportunidades que tivemos de entrar em contato com as organizações que ocupam aquele espaço. Atuando na praça, conseguimos dar significado político para nossas atividades e, partindo do referencial geográfico da Praça, nos aproximamos com as e os militantes envolvidos na questão migratória no município. Em 2012, o Educar para o Mundo teve a oportunidade de produzir um documentário sobre a Praça Kantuta em cooperação com o Instituto Criar de TV, Cinema e Novas Mídias - instituição que tem como missão promover o desenvolvimento profissional, sociocultural e pessoal de jovens por meio do audiovisual. A parceria envolveu oficinas com técnicas básicas de audiovisual com jovens migrantes da região cujo propósito central era trabalhar as noções de espaço público e identidade. Para isso, realizamos oficinas cinematográficas semanais, com a pretensão de inserir-nos gradativamente naquela comunidade e estabelecer bases de diálogo com os movimentos sociais de migrantes, sempre com a preocupação de realizar nossos trabalhos de forma horizontal e dialógica.

A oficina, cujo título era Mirando la Kantuta (em português, Olhares da Kantuta, mais tarde adotado como título do documentário produzido), acontecia durante a feira cultural aos domingos e propunha dois eixos de trabalho principais. No primeiro eixo, a oficina tinha um caráter técnico, visando ensinar os participantes, 
preferencialmente descendentes de imigrantes, a manipular câmeras e demais acessórios cinematográficos, e foi realizado pela equipe do Instituto Criar. Concomitantemente, o Educar para o Mundo direcionava o segundo eixo da oficina para realizar a reflexão sobre o papel da praça para a comunidade que ali residia ou circulava. $\mathrm{O}$ objetivo era discutir as primeiras impressões e os preconceitos sobre os migrantes, e questionar estas impressões, contrastando com a visão comum de serem os preconceitos imutáveis. Assim, muito mais do que o espaço de aprendizado técnico, as oficinas propunham aos jovens (público majoritário nas atividades) a apresentação e o questionamento de definições de identidade cultural e espaço público. Esse jogo reflexivo entre técnica e reflexão foi concretizado através da produção de dois documentário $^{* * *}$. O primeiro, produzido pelos próprios jovens, buscou transmitir olhares diversos sobre o espaço da Kantuta. A relevância do exercício aumenta porque consideramos que o conhecimento não é estanque, ao contrário, é constantemente modificado e substituído. Nesse sentido, a oficina é a expressão desse processo de modificação dos conceitos e do conhecimento pelo qual passaram seus participantes. O documentário mostra, através de entrevistas com comerciantes e transeuntes, múltiplas perspectivas sobre a Praça Kantuta e seus significados para aquela comunidade e ajuda a ressignificar a praça para os produtores do vídeo.

Figura 4 - Exibição dos documentários da oficina Mirando La Kantuta

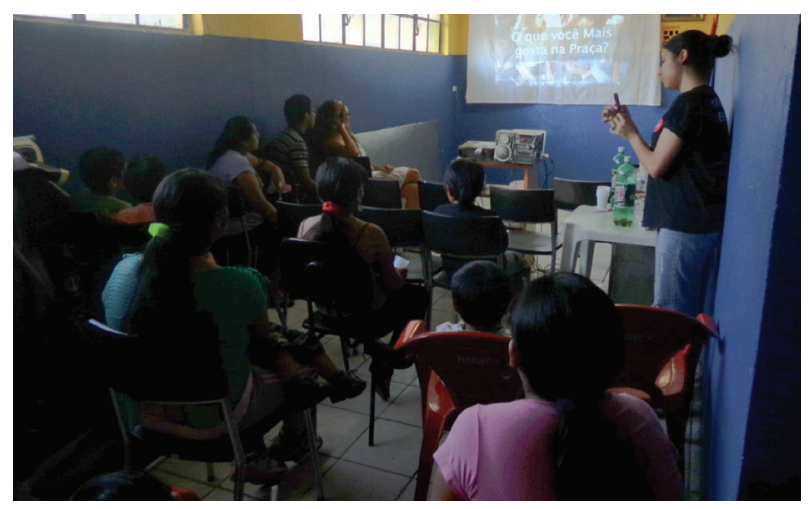

O segundo documentário é um registro sobre as atividades empreendidas pelos coletivos envolvidos, o Educar para o Mundo e o Instituto Criar. Seu foco é veicular as impressões e o impacto das oficinas, tanto em termos objetivos para as duas organizações, como em termos pessoais, para seus respectivos membros. Neste documentário, são expostos os desafios e as conquistas da inserção em um espaço físico e da construção de diálogos com as pessoas que ali vivem, procurando, em sintonia com a prática extensionista, que ocorra um debate horizontal e dialógico. Dentre as

\footnotetext{
*** O documentário Mirando la Kantuta (Olhares da Kantuta) pode ser assistido em: <https://www. youtube.com/watch?v=g7|W0-qSFol $>$ [15]. A perspectiva dos facilitadores das oficinas pode ser assistido em: <https://www.youtube.com/watch?v=xsf4nz-gYqw> [7]
} 
múltiplas impressões que vieram à tona durante nossa experiência e que são apresentadas no documentário, destaca-se a complexidade da relação imigrante-nacional. Inicialmente, nós, os locais, procurávamos um contato com o grupo migrante e forasteiro. Porém, o contato semanal com os migrantes acabou por promover a erosão de nossas preconcepções de forma a evidenciar que, na verdade, nós, erámos os forasteiros e nos encontrávamos em terra estranha, uma vez que o espaço pertencia de fato à comunidade migrante. $\mathrm{O}$ impacto dessa relação foi essencial para desmitificar estereótipos e nos possibilitou entender que a relação nacional-imigrante ultrapassa as fronteiras físicas entre os países. Essa ressignificação do que significa ser migrante é parte fundamental na construção da ponte de intercâmbio de conhecimento que pretendemos desenvolver ao adotar a educação popular e a extensão comunicativa como métodos.

\section{HORIZONTE FORMAL DE INTEGRAÇÃO ESTADO -} SOCIEDADE CIVIL - UNIVERSIDADE

Uma das ações mais recentes do Educar para o Mundo é a participação em um projeto em parceria do IRI-USP com a Secretaria Municipal de Direitos Humanos e Cidadania de São Paulo de acompanhamento para a criação e implementação da política migratória municipal junto aos atores sociais e governamentais. $\mathrm{O}$ projeto, chamado "São Paulo Cosmópolis", coordenado também pela Profa. Deisy Ventura, visa a promover a interação de três públicos: a comunidade acadêmica; a comunidade migrante e os movimentos sociais de imigrantes; e os órgãos governamentais envolvidos com a produção de políticas públicas migratórias.

O “Cosmópolis” planeja ações específicas para cada um desses públicos. Com a comunidade acadêmica planejamos criar uma disciplina optativa multidisciplinar de graduação sobre mobilidade humana, migrações e refúgio, com o acompanhamento da Comissão de Graduação, Cultura e Extensão do IRI, a fim de associar diretamente ensino e extensão. Além disso, pretende-se formar um grupo de estudos, aberto aos alunos de graduação e pós-graduação da USP, e em particular do IRI, para revisão da literatura sobre mobilidade humana e direitos dos imigrantes. Está planejada a organização de um evento acadêmico internacional sobre mobilidade humana, com o acompanhamento da Comissão de Pós-Graduação do IRI, a fim de entrelaçar iniciativas de pesquisa e de extensão. Além disso, as e os estudantes envolvidas(os) no projeto realizaram o mapeamento e diagnóstico da dinâmica entre a população migrante e os serviços públicos (onde estão mais presentes, quais dificuldades que enfrentam, quais pontos precisam melhorar, etc.), juntamente com a Coordenadoria de Políticas para Migrantes da Prefeitura de São Paulo e apresentaram os resultados na I Conferência Municipal de Políticas para Imigrantes.

Com as comunidades de migrantes e refugiados, planeja-se a organização de cursos de curta duração sobre mobilidade humana e direitos, construídos junto às comunidades de migrantes e refugiados, similares aos que já realizamos em 2012. Além disso, planeja-se desenvolver parcerias com organizações sociais e comunidades de 
imigrantes para realizar atividades de educação para os direitos humanos de crianças e adultos migrantes.

Para os servidores públicos municipais e outros atores governamentais e sociais que lidam diariamente com migrantes internacionais organizaremos cursos de capacitação para qualificar o atendimento a esta população, visando difundir as normas vigentes sobre imigração e melhorar o acolhimento de migrantes na cidade. A primeira oficina do tipo ocorreu dentro do curso de formação para guardas civis municipais da Prefeitura de São Paulo, chamado Mediação de Conflitos e a Promoção dos Direitos Humanos, com o tema Mediação de Conflitos Envolvendo Migrantes. Na oficina, o debate girou em torno de dados de imigração no Brasil e em São Paulo, dos principais direitos dos imigrantes e dos conflitos mais comuns que ocorrem com migrantes. $\mathrm{O}$ objetivo era discutir e capacitar os guardas civis municipais para atuarem na garantia dos direitos humanos dos imigrantes que se envolvem em conflitos. A questão do preconceito e da xenofobia foi também um dos assuntos debatidos a partir das experiências dos participantes da oficina.

Ainda na dimensão de integração entre Estado, Sociedade Civil e Universidade, o Educar para o Mundo participou da I Conferência Nacional de Imigração e Refúgio (Comigrar), que ocorreu no início de 2014, com uma delegação de representantes para a discussão das propostas de políticas para imigrantes. No evento, o EpM ofereceu uma oficina sobre Políticas Municipais para Migrantes. A oficina debateu a experiência da Prefeitura de São Paulo com a Coordenadoria de Políticas para Migrantes e a experiência de outros municípios e estados. Os temas principais foram as formas de participação política nos Conselhos Municipais com representantes de migrantes, maneiras de garantir a aplicação de políticas públicas voltadas para imigrantes e o compartilhamento de experiências entre os participantes, muitos deles representantes de governos municipais com interesse no tema.

O Educar para o Mundo também buscou promover a valorização da cultura migrante e sua integração com a cultura brasileira por meio do Sarau do Glicério, uma noite de apresentações culturais organizadas para os migrantes e com a participação dos migrantes que residiam no Abrigo Municipal do Glicério, em Junho de 2014. A atividade foi importante para promover um intercâmbio inicial entre as culturas migrantes e brasileira, para oferecer um momento de boas vindas e descontração para os abrigados, e para estabelecer contatos entre o EpM e novos grupos migrantes na cidade, como os refugiados haitianos, que formavam a maioria dos abrigados, seguidos de ganeses, senegalenses e congoleses.

Figura 5 - Sarau do Glicério no Abrigo Municipal do Glicério

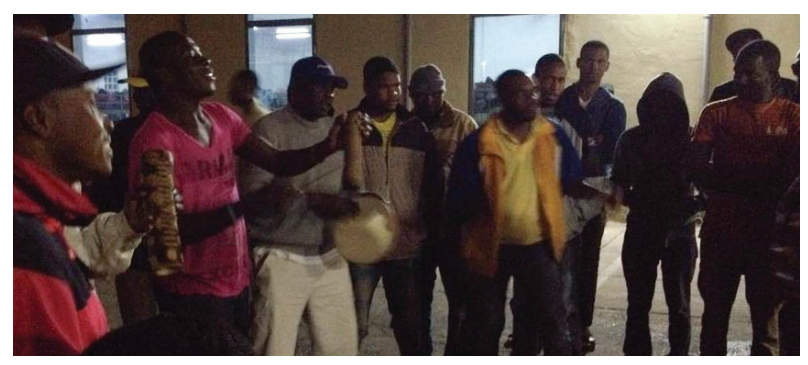


Neste artigo, através da descrição das atividades realizadas pelo Educar para o Mundo nos seus seis anos de existência e da apresentação de seus projetos futuros, buscamos discutir possibilidades para a prática extensionista em Relações Internacionais. Procuramos demonstrar algumas especificidades de projetos de extensão baseados no diálogo com seus interlocutores e debater a importância da adaptação do projeto às demandas que surgem deste diálogo. Em nosso caso, o projeto de extensão se localiza entre a comunidade migrante em São Paulo e a comunidade acadêmica.

Os espaços públicos ocupados por migrantes, bem como seus espaços de articulação, se mostram diversos, assim como devem ser diversas nossas formas de abordagem. Ainda que princípios freirianos de educação popular em direitos humanos e posições políticas do coletivo tornaram-se denominadores comuns em nosso trabalho, cada espaço ocupado e o perfil de cada um de nossos interlocutores exigem de nós a capacidade de ressignificar a extensão universitária em suas diversas dimensões.

A atuação na escola nos demandou entender e questionar a realidade do (filho do) migrante no ambiente escolar. O fato de lidarmos com vários estudantes, muitos deles não-migrantes, nos levou a focar os debates na interação do estudante migrante com os estudantes brasileiros e fez com que nossa atuação se expandisse para além dos direitos diretamente ligados à migração, resultando em oficinas sobre direitos humanos em uma concepção mais ampla. No curso do projeto, encontramos algumas barreiras com a estrutura formal do sistema educacional, que nos fizeram optar por redirecionar nossa atuação para espaços onde pudéssemos estar mais diretamente envolvidos com movimentos sociais dos migrantes.

Nossas atividades extensionistas em Relações Internacionais com os movimentos sociais dos migrantes consistem, essencialmente, em nossa participação no Fórum Social pela Integração e Direitos Humanos dos Migrantes, assim como nas Cúpulas Sociais do Mercosul, na construção de Marchas do Migrante, na realização de oficinas sobre legislação migratória brasileira e na articulação com os governos municipal e federal pela promoção dos direitos dos migrantes no Brasil. Em nosso trabalho, procuramos reconhecer que as demandas nesses espaços se referem a dilemas e dificuldades concretas que os migrantes vivem em seu dia a dia e com as quais o meio acadêmico costuma lidar de maneira superficial, ou secundária. Envolver-se com essas questões traz a tona novas perspectivas sobre as migrações e sobre o impacto que a integração e as políticas públicas têm no cotidiano dos imigrantes e cria novas possibilidades de pesquisa e de abordagem teórico-metodológicas para o campo.

O retorno oferecido para a Universidade e a comunidade acadêmica permite valorizar a visão dos imigrantes sobre as tensões e problemas de pesquisa que são analisados pelos pesquisadores e multiplicar os pontos de vista sobre a questão da imigração. O espaço de formação do estudante e pesquisador tanto na temática da imigração, quanto nas questões relacionadas com a extensão comunicativa, o diálogo horizontal como método e os debates sobre autogestão e educação popular desenvolvem habilidades pessoais e profissionais que permitem uma visão crítica sobre a realidade e aumentam a possibilidade de uma atuação transformadora na sociedade. 
Finalmente, gostaríamos de concluir com a defesa do papel que um coletivo universitário extensionista pode ter na sociedade, incidindo de fato no meio em que está inserido e o alterando significantemente. Reconhecemos que, além da importância da extensão comunicativa no diálogo político que se pretende estabelecer entre a sociedade civil e a universidade, o trabalho com a extensão popular apresenta uma contribuição para a articulação com governos e outras esferas da política institucional, transformando a relação e os conceitos previamente estabelecidos para esta articulação.

\section{REFERÊNCIAS}

[1] ASSEMBLEIA Geral da Organização das Nações Unidas. Declaração dos Direitos da Criança da ONU Adotada em 1959.

[2] BENEVIDES, M. V. Educação para a democracia. Lua Nova. Revista de Cultura e Política, v. 38, p. 223-237, 2004.

[3] BRANDÃO, C. R. Refletir, discutir, propor: as dimensões de militância intelectual que há no educador. In: BRANDÃO, Carlos R. (org.) O educador: vida e morte. São Paulo, Editora Graal, 1982, pp. 71-89.

[4] BRASIL, Câmara dos Deputados. (1980) Lei 6815/1980, Disponível em: <http://www2.camara.gov.br/legin/fed/lei/1980-1987/lei-6815-19-agosto1980-366138-norma-pl.html>

[5] BRASIL, Câmara dos Deputados. (2009) Projeto de Lei 5655/2009, Disponível em: <http://www.camara.gov.br/proposicoesWeb/fichadetramitacao?i dProposicao $=443102 .>$

[6] CANDAU, V. M. Direitos Humanos, Educação e Interculturalidade: as tensões entre igualdade e diferença. Revista Brasileira de Educação, v. 13, n. 37. 2008

[7] DOCUMENTÁRIO KANTUTA. Oficina "Olhares da Kantuta”(organizadores). Org.: Educar para o Mundo, e Instituto Criar de TV, Cinema e Novas Mídias. Brasil: 2012. Video disponibilizado na internet (6min 3seg): son., color. Port.

[8] ENTRE les Murs. Direção de Laurent Cantet. Produção de Caroline Benjo e Carole Scotta. França: 2008.

[9] ESCOLA MUNICIPAL DE ENSINO FUNDAMENTAL INFANTE DOM HENRIQUE. Inventário da presença migrante na EMEF Infante D. Henrique (mimeo). São Paulo, 2009.

[10] FREIRE, P. Extensão ou comunicação? 10. ed. Rio de Janeiro, Paz e Terra, 1977.

[11] Educar. O sonho possível. In: BRANDÃO, Carlos R. (org.) O educador: vida e morte. São Paulo, Editora Graal, 1982, pp. 89-103.

[12] . Pedagogia do oprimido. Rio de Janeiro: Paz e Terra, 1994.

[13] MAGALHÃES, G. M. Fronteiras do direito humano à educação: um estudo sobre os imigrantes bolivianos nas escolas públicas de São Paulo. Dissertação (Mestre em Educação) - Faculdade de Educação, Universidade de São Paulo, São Paulo, 2010. 
[14] MASTELARO, C.; OTERO, G. A. P.; BRAGA, R. S., FIRBIDA, T. P., SANTOS, T. H. Extensão em relações internacionais: por uma nova práxis. Revista Direito \& Sensibilidade v.1, n.1, 2011. Disponível em: <http://periodicos.unb. br/index.php/enedex/article/view/4309>

[15] MIRANDO LA KANTUTA. Oficina "Olhares da Kantuta"(participantes). Org.: Educar para o Mundo, e Instituto Criar de TV, Cinema e Novas Mídias. Brasil: 2012. Video disponibilizado na internet (3min 51seg): son., color. Port.

[16] MORAES, I. Educar para o Mundo. Extensão em Relações Internacionais: Direitos Humanos e Imigração em São Paulo. Revista Ideias. v. 1, n. 5, 2012. Disponível em < http://www.ifch.unicamp.br/ojs/index.php/ideias/article/ view/1039/737> Acessado em: 30 jun. 13

[17] PIMENTEL, C.; TAMI, J. A chegada dos imigrantes. Revista Educação, edição 174. São Paulo: Editora Segmento, out. 2011.

EDUCAR PARA O MUNDO (EPM) é um coletivo de extensão universitária do Instituto de Relações Internacionais da Universidade de São Paulo (IRI-USP) que atua com educação popular em Direitos Humanos, junto à população migrante de São Paulo - e-mail: epm.guima@gmail.com - blog: $<$ educarparaomundo.wordpress.com>

ALLAN GREICON MACEDO LIMA graduando em Relações Internacionais no Instituto de Relações Internacionais da Universidade de São Paulo (IRI-USP)e atua no EpM desde 2011 - e-mail: allangreicon@gmail.com

ANA CAROLINA MAZZOTINI graduanda em Relações Internacionais no Instituto de Relações Internacionais da Universidade de São Paulo (IRI-USP) e atua no EpM desde 2012 - e-mail: cah. mazzo@gmail.com

AUGUSTO MALAMAN graduando em Relações Internacionais no Instituto de Relações Internacionais da Universidade de São Paulo (IRI-USP) e atua no EpM desde 2012 - e-mail: augustoct261@gmail.com

AUGUSTO VELOSO LEÃO doutorando em Relações Internacionais no Instituto de Relações Internacionais da Universidade de São Paulo (IRI-USP) e atua no EpM desde 2010 - e-mail: augustovl@usp.br

CAIO MADER graduanda em Relações Internacionais no Instituto de Relações Internacionais da Universidade de São Paulo (IRI-USP) e atua no EpM desde 2012 - e-mail: caiomader16@gmail.com

CAROLINA TAKAHASHI graduanda em Relações Internacionais no Instituto de Relações Internacionais da Universidade de São Paulo (IRI-USP) e atua no EpM desde 2013 - e-mail: carolmtakahashi@ gmail.com 
CLAUDIO CAVALCANTE graduando em Relações Internacionais no Instituto de Relações Internacionais da Universidade de São Paulo (IRI-USP) e atua no EpM desde 2013-e-mail: cavalcanteoo95@gmail. com

GUILHERME AROSA OTERO graduado em Relações Internacionais no Instituto de Relações Internacionais da USP e Assessor da Coordenação de Políticas para Migrantes da Secretaria Municipal de Direitos Humanos e Cidadania de São Paulo. Atua no EpM desde 2009 - e-mail: gapotero@gmail. com

GUSTAVO PEREIRA graduando em Relações Internacionais no Instituto de Relações Internacionais da Universidade de São Paulo (IRI-USP) e atua no EpM desde 2013 - e-mail: gustavopmms1@gmail.com

HUGO SALUSTIANO graduando em Relações Internacionais no Instituto de Relações Internacionais da Universidade de São Paulo (IRI-USP) e atua no EpM desde 2013 - e-mail: hugosalustiano@gmail.com

MARTIN EGON MAITINO graduando em Relações Internacionais no Instituto de Relações Internacionais da Universidade de São Paulo (IRI-USP) e atua no EpM desde 2013 - e-mail: martin. maitino@gmail.com

NATÁLIA LIMA DE ARAÚJO graduanda em Relações Internacionais no Instituto de Relações Internacionais da Universidade de São Paulo (IRI-USP) e atua no EpM desde 2011 - e-mail: natalia. lima.araujo@gmail.com

PHILLIP WILLIANS graduando em Relações Internacionais no Instituto de Relações Internacionais da Universidade de São Paulo (IRI-USP) e atua no EpM desde 2013 -e-mail: phillipwleit@gmail.com 